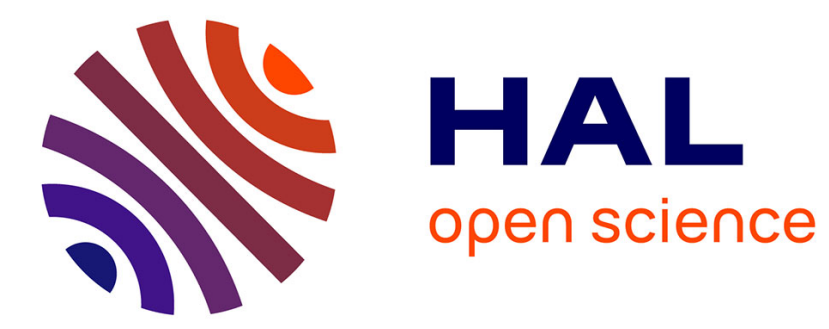

\title{
Plus qu'une langue: The construction of identity via French as an additional language in Hong Kong
}

Lorraine de Beaufort

\section{To cite this version:}

Lorraine de Beaufort. Plus qu'une langue: The construction of identity via French as an additional language in Hong Kong. International Journal of Multilingualism, 2019, pp.1-19. 10.1080/14790718.2019.1629936 . hal-02490775

\section{HAL Id: hal-02490775 \\ https://hal.science/hal-02490775}

Submitted on 25 Feb 2020

HAL is a multi-disciplinary open access archive for the deposit and dissemination of scientific research documents, whether they are published or not. The documents may come from teaching and research institutions in France or abroad, or from public or private research centers.
L'archive ouverte pluridisciplinaire $\mathbf{H A L}$, est destinée au dépôt et à la diffusion de documents scientifiques de niveau recherche, publiés ou non, émanant des établissements d'enseignement et de recherche français ou étrangers, des laboratoires publics ou privés. 
This is an Author's Original Manuscript of an article published by Taylor \& Francis in International Journal of Multilingualism on 23 Jun 2019, available online https://www.tandfonline.com/doi/full/ 10.1080/14790718.2019.1629936

Plus qu'une langue: The construction of identity via French as an additional language in

\section{Hong Kong}

Lorraine de Beaufort

Currently affiliated to:

Department of English Language Education, Education University of Hong Kong, Tai Po, N.T., Hong Kong

and

Université de Lorraine, Laboratoire ATILF, UMR 7118, Université de Lorraine, 44 avenue de la Libération, 54000 Nancy, France

Email: lorrainedebeaufort@gmail.com

Mobile: +85264918749 


\begin{abstract}
There is a great deal of research literature that treats language learning as a process of identity construction, but relatively few studies have investigated so-called additional languages. This article presents interview and other narrative data from a single language learner studying French as an additional language in Hong Kong. Using the methodological approach of narrative inquiry, it explores the relationship between additional language learning and identity. The data show how additional language learning plays a significant role in identity construction, and the discussion highlights three aspects of this relationship. First, the process of learning is revealed as being one of growing intercultural awareness. This is seen as an identity-related disposition that can be used to deal with certain aspects of the learner's own cultural environment. Second, the creative appropriation of an additional language is an affordance for identity construction, despite limited levels of conventional proficiency. Third, the significance of particular languages and their associated cultures is constructed in relation to other languages in the language ecology. In addition to illustrating these aspects of language learning in the age of globalisation, the article briefly considers the pedagogical implications of taking an identity-based perspective on language learning.
\end{abstract}

Keywords: identity; language learning; additional languages; French learning; narrative inquiry

\title{
Introduction
}

It is by now a commonplace to say that language learning is also a process of identity construction (e.g., Block, 2007; Norton \& Toohey, 2011). However, in Asia, studies of the relationship between the two have mainly focused on what might be called the dominant languages in the language ecology (e.g., Gu, 2010 on English in China, and Gu, 2011 on English, Cantonese and Putonghua among students in Hong Kong). Less attention has been given to the learning of additional languages, defined here as languages that do not have well-defined roles in a particular context and are often, but not necessarily, learned in addition to dominant languages. In Hong Kong, for example, French can be classified as an additional language, learned in addition to the official languages of Chinese (Cantonese and Putonghua) and English, and studied mainly on a voluntary or elective basis.

This article focuses on the learning of French in Hong Kong and examines its relationship with learner identity, highlighting the particularities of additional languages as defined in this study. It also contends that the Hong Kong context illustrates several aspects of language learning under conditions of globalization and provides a deeper insight into processes of identity formation under these conditions. The central argument is that although French meets the definition of an additional language in Hong Kong, and although many learners do not attain a high level of proficiency in conventional terms, it can still provide significant resources for the construction of identity. The study draws on extensive interview data and adopts the methodological approach of narrative inquiry (e.g., Clandinin, 2013; Clandinin \& Connelly, 2000; Barkhuizen et al., 2014). The data presented here comes from a single learner (Yasmina) and consists of excerpts from language learning narratives that were collected over a period of two years. The analysis elaborates on the roles played by French (and other languages) in processes of identity formation, and identifies three aspects of additional language learning that are particularly 
distinctive and which may tell us more about language learning in general under contemporary conditions. The discussion section of the article contextualises the study with regard to recent research in the field of language and globalization, and the implications for the teaching and learning of additional languages are also briefly considered.

\section{Conceptual framework: identity and language learning}

There is considerable research interest in viewing language acquisition from the perspective of identity (e.g., Norton, 2000, 2012; Morita, 2004; Toohey, 2000; Pavlenko \& Norton, 2007). Norton (2012) identifies some of the distinctive features of her identity-based approach, which draws on poststructuralist influences (e.g., Weedon, 1987). First, individuals and their identities are seen as diverse and dynamic, rather than unitary and stable (Pavlenko, 2002, p. 286). Second, identity-based approaches emphasise the contested and heterogeneous aspects of language, in place of consensual communities and shared language systems (Norton, 2012, p.2). Third, researchers interested in identity see language learning as a dynamic social practice (see, e.g., Pennycook, 2010; Byrd Clark, 2012) rather than as 'individual minds acquiring linguistic, or even sociolinguistic, competence' (Norton, 2012, p. 3).

The identity-based perspective taken by Norton and her collaborators sees the learning of another language as reflecting 'the desire of learners to expand their range of identities and to reach out to wider worlds' (Pavlenko \& Norton, 2007, p. 670). This 'reaching out' can be seen as occurring in spatial dimensions (e.g., when learners travel abroad) and in temporal dimensions (e.g., when learners reflect upon their past learning experiences, take stock of present conditions, or consider future possibilities; see Canagarajah \& De Costa, 2016 and Wortham, 2005 for further illustration of the spatial and temporal dimensions). Contemporary conditions of globalization have greatly increased the reach of global media and digital interaction, extending the range of possibilities for 'reaching out' and creating an 'expanded space of self-authoring' (Francis, 2010, pp. 126-127). In spatial terms people increasingly encounter 'global' influences in their 'local' cultural milieu, and temporally there is an expanded range of future possibilities, especially if imagination is taken into account. Combining the spatial and temporal dimensions, Kanno and Norton (2003) observe that imagination allows the language learner to envision himself or herself taking part in 'future relationships that exist only in [his/her] imagination as well as affiliations - such as nationhood or even transnational communities - that extend beyond local sets of relationships' (p. 242).

Norton's work on identity also introduced the concept of investment (see, e.g., Norton, 2000, 2012; Darvin \& Norton, 2015), and the investment metaphor can be useful in understanding the decisions made by language learners. However, and although the learners in this study could be viewed as making investments in French (and/or in their own identities), I chose not to foreground the concept in order to avoid imposing a pre-existing framework on the learners' narrative accounts. The methodological approach of narrative inquiry also led me to acknowledge that the connections between individuals' past, present and future selves are not always predictable (Eakin, 1999, in Menard-Warwick, 2005, p. 267), and I found the approach taken by the poststructuralist perspective of Benson et al. $(2013$, p. 19) to be more compatible. The multiple facets of identity in this approach include 'reflexive' identity (the 'self's view of the self', including its attributes and capacities), 'imagined' identity (the 'self's view of its future 
possibilities'), recognized identity (the self as conceived by others) and 'projected identity' (the self as represented to others). As Bucholtz and Hall (2005) observe, 'it is not a matter of choosing one dimension of identity over others, but of considering multiple facets in order to achieve a more complete understanding of how identity works' (p. 593).

\section{Additional languages and identity}

As mentioned above, relatively few studies of the relationship between language learning and identity have focused on additional languages. The category 'additional language' is somewhat difficult to define as it depends on both context-related and learner-related factors (for commentary, see Hammarberg, 2011; Jessner, 2008). Here I define it as a language that is learned in addition to the official or dominant languages of a particular context (see De Angelis, 2007). I use the term in preference to 'second language' or 'foreign language' partly because it does not make a priori assumptions about the actual roles these languages play in learners' lives and partly because for the learners in this Hong Kong-based study, French has only peripheral status in their undergraduate programme. In this setting, additional languages such as French, German or Japanese are learned on a voluntary or non-compulsory basis. Part of the rationale for the study is, however, to find out what this 'voluntarism' means in practice, highlighting the particularities of additional language learning and identifying what this can tell us about the relationship between language learning and identity under contemporary conditions. Clarke and Hennig (2013) draw attention to the 'voluntary' aspect of additional language learning, noting that this can assist in understanding 'how learning can support learners in their self-development and the formation of their "selves", in ways not necessarily linked to necessity, struggle and survival' (p. 79).

Among previous studies of the relationship between additional languages and identity, Coffey (2010) took a narrative approach by interviewing six British learners of French and investigated 'how participants integrated images of France and "Frenchness" into their own autobiographical accounts' (Coffey, 2010, p. 129). The temporal dimension - past, present and future - of this discursive process of identity construction is visible in the observation that identities are not (only) retrospective but signal current interactional identity positions and anticipate projected future identities' (Coffey, 2010, p. 121). The participants constructed their identities in a relational manner, using the narrative device of 'difference/opposition' so that 'what is attractive about (experience of) France is commensurate with what is unattractive about (experience of) England' (Coffey, 2010, p. 126). In addition to highlighting the relational aspect of identity (see also Bucholtz \& Hall, 2005), Coffey's study also illustrates the important role played by turning points in life trajectories and narrative studies (e.g., Bruner, 2001; Mishler, 2006). For Coffey's learners the major turning point was their experience of visiting France. Kinginger (2004) focuses on one learner (Alice) and shows how she renegotiates her identity through learning French, which is perceived as a source of cultural capital in her country of origin (the US).

However, for the foreign language learners in both Coffey's and Kinginger's studies, the experience of visiting France was central to their renegotiation of identity. This renegotiation was thus largely achieved through active participation (or active non-participation) in various pre-existing communities of practice. In the present study, by way of contrast, the focus is on the relationship between language learning and identity in an environment (Hong Kong) that does not immediately present such opportunities or communities of practice, and in which learners' 
engagement with the language is largely achieved through imagination ('a process of expanding our time and space and creating new images of the world and ourselves'; Wenger 1998, p.176). This is not so unusual under conditions of globalisation, as Pavlenko (2002) observes: 'in the global picture ... millions of people learn and use additional languages without giving a thought to those who could be considered a TL group' (p. 279). Imagination is thus seen as a resource for the potential formation of new communities of practice - online or offline, temporary or durable, intense or 'light', to adopt Blommaert and Varis's (2015, p. 49) term.

There have been relatively few studies of additional languages and identity in Asia. Dreyer (2009) studied French learners in Taiwan, but used the concept of 'existential motivation' instead of identity. The Hong Kong-based study of Hennig (2010), which focused on twelve learners of German, was also based on motivation rather than identity. However, Hennig's interview data show that learning an additional language involves identity repositioning ('notions of selfstylisation and distinction', p. 307) and a different sense of belonging. As in Coffey's study, there is a relational interplay between representations of the local culture and the (often idealized) culture associated with the additional language, as learners gain 'a sense of societal and cultural belonging through identification or non-identification with certain ethical and sociocultural values of the local culture as well as that of the target language' (Hennig, 2010, p. $313)$.

Something that these previous studies have in common is that they have once again tended to assume the prior existence of largely fixed communities, languages, and cultures, for example by focusing on culturally-shared perceptions and stereotypes. Coffey (2010) notes that ' $[\mathrm{t}] \mathrm{he}$ learning language autobiographies I analysed drew on shared cultural repertoires of the appeal of French, repertoires which may be subconscious but which underpin the passion for learning French as an autobiographical identity project' (p. 125). Kinginger (2004) notes how Alice's aspirations reflect 'ideologies of French language promulgated by representatives of the "Francophonie" movement' (p.228), and Hennig (2010) sees the learners as 'relying on simplifications, over-generalisations and stereotype pictures in drawing an image of the country of the target language' (p. 119).

While shared cultural repertoires or ideologies certainly exist and can be used as 'resources for identity work' (Bucholz \& Hall 2005, 588), as indeed they are in the present study, it is also desirable for researchers to examine the ways in which these resources are taken up and negotiated by individuals. As De Fina (2006) notes, analysts need to go beyond 'easy generalizations about the way communities portray themselves and their relationships with others' (p. 374). In the context of additional language learning, such generalizations might include stereotypes of 'French sophistication' or 'German toughness", or of a homogeneous 'local culture'. The present study therefore attempts to go beyond these stereotypes and obtain more fine-grained and revealing data on the relationships between identity and the learning of an additional language, partly by focusing in detail on the language learning narratives of a single learner. The researcher developed a close relationship with the participant over the course of the study, and the interviews encouraged her to reflect not only on the instrumental or integrative reasons, but also on the emotional tensions and sociohistorical events that accompanied her involvement with additional languages. Before introducing the research methodology (narrative inquiry) and the participant, I will first characterize the context of the study. 


\section{The Hong Kong context}

Hong Kong represents an interesting case study of how the processes of globalisation influence language learning. In economic terms Hong Kong has long positioned itself as a bridge between China and the rest of the world. There is considerable mobility, both in the sense of actual migration (e.g., overseas exchanges, which are compulsory at many universities) and the migration of ideas (e.g., Hong Kong has one of the highest rates of smartphone use in the world; see 'The Asian mobile consumer decoded', 2014). Hong Kong illustrates the identity possibilities that exist for relatively privileged individuals in today's interconnected world, and also the imaginative possibilities opened up by the internet.

Hong Kong's official language policy aim is one of biliteracy in English and Chinese and trilingualism in English, Cantonese and Putonghua/Mandarin. Within the mainly Englishmedium higher education system, many university students choose to study an additional language, with Japanese being a popular choice (Humphreys \& Spratt, 2008, p. 322). As there are relatively few opportunities for encountering or using these languages, the role played by perceptions and images of languages and their associated cultures is important in explaining these choices and understanding what occurs during language learning (Coffey (2010, p. 127). Hennig (2010) further points out that the process of identity construction involves not only perceptions of the target language and its associated culture, but also of the learners' own language and culture. Again, Hong Kong is an interesting place in which to study these interrelationships. There has long been tension between the 'local' and the 'global' aspects of Hong Kong's complex and multifaceted identity. The local poet Louise Ho has described Hong Kong as a 'geographic, cultural and political anomaly', in its essential nature 'a cosmopolitan city with a rock-hard Chinese core' (Ho, 2000, p. 382). The 1997 return of sovereignty to the People's Republic has added another dimension to the notion of Chineseness, and tensions exist between (and also within) groups of Beijing 'loyalists' and Hong Kong 'localists' (see Bland, 2017 for commentary on Hong Kong's contested identity). The student protests of 2014 brought these tensions to the fore, as well as highlighting generational divides in terms of social and political attitudes.

\section{Methodology and data collection}

This paper draws on data from one of the participants in a larger research project which investigated the role of French in the lives of twelve Hong Kong students (ten female and two male) over a period of two years. All of the participants agreed to take part in the study by responding to an initial inquiry. Of this group of participants, who first became known to me through either my teaching or my research-related classroom observations, five female participants went through the complete process of data collection and analysis. The narrowing of the participant group reflected the intensive and time-consuming nature of narrative inquiry, which involves extensive data collection across multiple data sources and close relationships between researchers and participants.

Narrative inquiry has been described by Clandinin (2013, p. 38) as a way of 'thinking narratively' about people's experiences. It can have both descriptive and explanatory orientations. The descriptive orientation aims to render the narrative accounts that are used by individuals and groups for 'ordering and making temporal events meaningful' (Polkinghorne, 
1988, p. 161). The explanatory orientation 'ties together and orders' events in order to investigate causation - note, however, that the epistemology of narrative inquiry treats concepts such as 'cause', 'validity' and 'explanation' in a very different way to that of positivist science (Polkinghorne 1988, p. 161). Indeed, the constructivist foundations of narrative inquiry tend to preclude some of the methodological preferences of positivism, including pre-determined research questions ('narrative inquirers do not come with questions'; Clandinin, 2013, p.51). The initial research orientation of the larger study was thus simply to explore the meaning of learning French as an additional language in a particular place, at a particular time. However, and as outlined above in the Introduction, the three main foci of this article are (1) the ways in which the learning of French as an additional language contributes to processes of identity formation; (2) what this can tell us about language learning under contemporary conditions; and (3) the possible implications for language teaching. With regard to (2) and (3), it must also be noted that narrative inquiry does not aim for 'generalisability', but rather 'transferability' (Lincoln \& Guba, 1985). Transferability refers to the relevance of findings 'for understanding similar issues and processes involved in other situations' (Barbour, 2000, p.158) and is achieved by detailed, 'thick' description of 'the context and the actions situated within that context' (Loh, 2013, p.10).

Data collection instruments included written language learner histories (LLHs; Mercer, 2013) providing details of previous language learning experiences, three in-depth interviews, and written techno-linguistic reports (TLRs) in which the participants recorded online learning activities in several languages including French. Apart from these sources of data, I communicated frequently with the participants via social networks and via email and met informally outside scheduled interviews. I also collected artifacts and wrote notes and memos recording my thoughts throughout the inquiry period.

The three in-depth interviews were conducted over a period of a year and a half, and lasted between one and a half and two hours. Interviews were conducted in English. The interviews were intended to explore the participants' experiences of language learning in relation to various aspects of their personal trajectories. Each interview began with an explanation of its intended scope, but interview guides served more as prompts for the researcher (Barbour, 2008, 115) than as a 'road map' (Shedivy, 2004, 107). An example of an open-ended question prompt was 'Tell me more about your decision to start learning French'. As in any interview, my background and perceived identity (former teacher, French national, etc.) will have influenced the storytelling and its interpretation. Schiff and Noy (2006) remind us that both the story and its telling are influenced 'not only by the speaker, her life experience and storytelling intentions, but also by the listener' (p. 454; see also Mishler, 2006). However, narrative inquiry encourages, and in fact requires, the co-construction of narrative accounts by researcher and participant; it does not seek to objectify the participant or their experiences, but rather to reconstruct the experience with the participant in a collaborative process (Connelly \& Clandinin, 1990, p. 5). At the epistemological level, the acknowledgment of co-construction reflects an 'emerging consensus' among qualitative researchers that an interview is 'a joint accomplishment of the interviewer and interviewee' (Wells, 2011, p.27). In this study, the emerging narratives involved 'a high level of discursive collaboration' as opposed to being simply 'told' to the researcher (Barkhuizen, 2011, p.398). My positionality as a researcher varied according to the stage of the study, but the roles included those of 'befriender' and 'resource' (Sarangi \& Candlin, 2003, pp.278-279). The former role reflects narrative inquiry's emphasis on collaboration, and the latter alludes not only to the fact that I became an informant regarding French language and culture for the participants but also 'a source of insights' for the participants (Clandinin \& Rosiek, 2007, p.17) 


\section{Data analysis}

The data in the present paper comes from Yasmina, who was the first participant for whom I completed the process of data collection and analysis outlined above. The space limitations imposed by the article format provide one reason for focusing on a single participant, but in addition, including biographical details and extensive data from one participant allows for the kind of 'contextual depth' and 'holistic understanding' that De Costa (2010, p.524) argues are desirable in tracing learner trajectories. Duff (2014) points out that 'single-case studies permit elaboration on the complexity and characteristics of that one case, much as biographies allow readers to understand the fullness of a single subject's life' (p.6). Other studies based on the narratives of single learners include Barkhuizen (2009), Gao (2010), and Kinginger (2004).

I began the process of data analysis by actively listening back to the interview recordings and checking the transcriptions. The identification of 'narrative segments' (Riessman 1993, p.58) reflected instances where participants moved into storytelling mode, forming 'short stories' (Barkuizen, 2016, 2017) within larger narrative structures. These segments often hinted at issues of power and inequality, and gave indications of how participants dealt with (or wanted to be seen to deal with) these issues. They also allowed for the identification of 'turning points' (explained above). The interview data were combined with other data sources and analysed within a metaphorical three-dimensional analytical framework or narrative inquiry space (Clandinin \& Connelly, 2000, p. 50). The dimension of time (the 'when') includes memories and stories of the past, current experiences and imagined future plot lines. The dimension of space (the 'where') represents the spatial boundaries within which the actions take place. The dimension of sociality (the 'who' or 'what') includes the 'outward' aspect of the social environment (other people and their intentions, purposes, and points of view) and an 'inward' aspect which takes account of personal reactions to this changing environment. All three dimensions are inter-related and Clandinin and Connelly (2000) note that it is the work of the narrative inquirer to connect these 'disparate, but intimately connected matters in the threedimensional inquiry space’ (p. 146).

Analysing narrative data thus involves capturing the strands of human experience and weaving them into a coherent narrative. By tabulating chronological stages and events along with relevant aspects of content and context, connections were made between events and I eventually produced an initial research text (IRT) which attempted to bring the different strands of participants' stories together into a single coherent narrative. IRTs are described by Clandinin (2013, p.47) as 'partial texts' that are intended to allow researchers and participants to further co-construct the emerging narrative. The IRT was shared with each participant and followed up by a meeting in which the text was discussed, thus providing an important element of 'member checking' (Lincoln \& Guba, 1985, p.314).

Moving from data to field texts, to IRT and then ultimately to a final research text involves a process of 'back and forthing' (Clandinin \& Connelly, 2000, p. 138) in which the researcher moves recursively between field texts and emerging representations of the stories. In this process, new ways of understanding the data emerge and a plotline starts to appear. The final research text combines the different parts of the story, aiming for a 'plausible' story line or plot that serves to 'configure or compose the disparate data elements into a meaningful explanation of 
the protagonist's responses and actions' (Polkinghorne, 1995, pp.18-19).

\section{The participant: Yasmina's story of language learning}

Yasmina was 24 years old at the time of data collection. I first met Yasmina in 2012 when she enrolled in two of my French beginner courses during her final year at university. At the end of that year, she enrolled in an intensive summer French course in France and we kept in touch through Facebook during and after her trip abroad. I contacted her again in the autumn of 2014, asking if she would be willing to take part in the study. She responded positively and we met in April 2015 for the first interview.

Yasmina was born in southern China, where a local Chinese language (not Cantonese) was the main home language. Yasmina's family moved to Hong Kong when she was three years old, and Yasmina describes bad memories of having struggled to enter kindergarten, because of not knowing Cantonese. Her primary school was a Chinese-medium of instruction (CMI) school where she considered her spoken English to be better than average. She credited this to having lived in a multilingual environment during childhood, thanks to her Filipina maid who communicated with her in English and Tagalog. Following her mother's wishes, she was then enrolled in a private Catholic secondary school where the medium of instruction was English. Here she found that 'the whole situation twisted' (interview 2) because her classmates had a much higher level of English.

The first additional language Yasmina studied was Japanese. During her difficult secondary school years, Yasmina became interested in a charismatic Japanese singer and engaged in intense self-learning of the Japanese language. She has visited Japan several times and continues to attend a private lesson every weekend. Yasmina also took an introductory course in French at secondary school and enrolled in a French beginner course during her final year of university. This was partly because of her interest in French cinema (she took a course in cinema studies as part of her degree programme), and partly because it was linked to a three-week follow-up course at a university in France; she felt that it was important to have a study abroad experience while at university. On her return to Hong Kong she started working in arts-related employment. She was too busy to devote much time to learning French, but she enrolled in a short course at a local institute during the autumn of 2015.

\section{The role of French}

During the process of exploring the three-dimensional narrative space and producing a plotline for Yasmina, I focused not only on the participant's processes of identity construction but also on the role of the entity 'French'. The overall aim was to characterize the role played by conceptions and experiences of French (and other additional languages) in Yasmina's journey of language learning, and to try to understand why Yasmina's stories of language learning, along with the processes of identity construction they indicated, had unfolded as they did. Accordingly, I developed the idea of French being plus qu'une langue ('more than a language') in three different ways, each drawing on a slightly different meaning of the French phrase and illustrating different aspects of the relationship between additional language learning and identity construction. The sections below present extracts from Yasmina's narrative data using the three 
senses of plus qu'une langue as a framing device, with additional reference to the threedimensional narrative space as necessary. The source of the data is indicated using the codes LLH (language learning history), TLR (techno-linguistic report) and INT1, INT2 and INT3 for the three interviews.

\section{Plus qu'une langue 1: more than just a language}

An additional language may be plus qu'une langue - more than just a language - in several ways. Additional language learning generates significant affordances for identity construction, for example by contributing to the reflexive aspect of identity, which includes 'skills, capacities and powers' (Harré 2001, p. 61, in Benson et al. 2013, p. 20). Additional language learning provides resources for discovering and coping with one's own culture - its positive and negative aspects - by comparing it with and drawing inspiration from other cultures. Crucially, these affordances do not necessarily exist in direct proportion to levels of proficiency in conventional terms.

Yasmina's narratives show that languages, including additional languages, have played a significant role in her life. The biographical factors and events mentioned above - immigrating from mainland China as a small girl, not speaking Cantonese, having a lower level of English than her classmates - have led to Yasmina feeling that she is something of an outsider in her own culture. Here Yasmina recounts an experience in secondary school:

I was in the left behind group among different classes because my class was characterized as the bad class... we were black-listed [...] And sometimes the teachers or the adults $[\ldots]$ they make me feel inferior, not comparable to other students (INT1)

This comment illustrates Wortham's (2004) identification of the reciprocal relationship between institutionally-generated identities - i.e., recognized identities, in Benson et al.'s (2013) terms and individually-held or reflexive identities. Yasmina was dissatisfied with the institutionallyimposed identities based on her existing languages, and the stage was therefore set for an agentic 'reaching out'. For Yasmina, a major turning point in these troubled years was her discovery of Sheena Ringo, a Japanese singer. Referring to one of Ringo's songs (Kabukichou no Joou), Yasmina recalls how the singer's portrayals of outsiders changed her perspective:

I was very surprised by how... how... things could be perceived in childhood in this way and... actually she looks in different kinds of issues like religion and also most of songs are about sex and even about drugs [...] she gives me a different perspective to think at least in that early age of teenage life (INT1)

Yasmina went on to elaborate on how this discovery led to her being more critical, and perhaps more confident in voicing her opinions: 'it's not really shameful or not a good thing to stand up for your own stand and I think that changes me' (INT1).

An initial indication of the three-dimensional narrative inquiry space, then, is that the reaching out to other languages and cultures leads to an imaginative reconstruction of the 'local' culture and one's relationships with it, thus affecting reflexive and imaginative identity. This process of reconstruction continued at university, when Yasmina chose to study French during her final 
year. Here a temporal turning point was noticeable in the form of a 'study abroad' experience, in Yasmina's case a summer course at a French university. One aspect of her narrative account is the tension between freedom and conformity:

In general, France this country provided a shelter to me [...] even I had to follow the schedule assigned by the school I can still manage it [...] because I feel so relaxed and I gained weight in France [...] I feel free to make every decision (INT2)

The perception of freedom was contrasted with the 'limitations' she associated with Hong Kong, for example the stigma attached to going to a concert alone (INT2). This illustrates the relational aspect of identity noted by Coffey (2010), in which the perceived attractiveness of another culture is related to what is seen as unattractive about one's own culture. As Mishler's (2006) comment on the 'reframing' (p. 36) of experiences in narratives suggests, Yasmina's recollection of her time in France was perhaps influenced by work-related events around the time of the interview. When Yasmina describes her experiences at work in Hong Kong, some of the themes from earlier biographical stages - of perceived difference from the group, of the tension between freedom and conformity - reappear.

At work, she was finding it hard to reconcile the tension between having to fit into the team and needing to defend her own ideas. This came to the fore during discussions with colleagues about the future of Hong Kong during the student-led protest movement in 2014. At this point the spatial and temporal dimensions of narrative inquiry space are useful orientational devices, as this movement (and its counter-movement) were in effect a clash between opposing points of view about the nature of Hong Kong's metaphorical boundaries and its possible futures.

Here Yasmina narrates what happened after a work lunch, in which she felt she disagreed with the mainstream view of the 2014 student protests but did not articulate her opinions:

I feel kind of ashamed that I didn't speak up in that luncheon and I'm glad that I didn't speak up because of course I will have a hard time afterwards [...] but I don't know why I feel so ashamed at that time... because I feel so lonely in that luncheon and most of them... my colleagues [...] they just think that "Why do the students have to do this?" $[\ldots]$ as $[\ldots]$ a young person in the society, we have another interpretation and we want another life (INT1)

Clarifying the role played by additional languages in managing this tension, Yasmina suggested that knowing an additional language such as Japanese or French provided resources that allowed her to see the situation differently:

I don't know is learning another additional language as a way to escape from the current culture that I am living with [...] I am finding some other perspectives or some other alternatives of living through learning languages (INT1)

These 'other perspectives' do not necessarily involve the use of additional languages, but rather the exploitation of the various insights - intercultural, interpersonal and psychological - that studying them and experiencing their associated cultures provides. For Yasmina, resolving the tension does not mean rejecting the local culture, but rather finding ways to deal with its impositions. 
In identifying these aspects of the relationship between language learning and identity, captured by the three senses of plus qu'une langue, I have drawn upon my earlier tabular analyses of the three-dimensional narrative space created by the participants. For example, the when dimension of Yasmina's narratives includes her personal biography (e.g., starting work after graduating in 2014, after having studied Japanese and French, visiting France, etc.), the institutional timescales of her workplace, and the longer-term discourses of national identity and belonging (themselves arising from historical phases such as colonization and the resumption of sovereignty). The where dimension ranges from the lunch restaurant to the workplace and again to Hong Kong itself, the latter being subject to contesting views of 'location' (inside or outside China) at that time. The who dimension includes Yasmina's feelings of exclusion and silencing, her classmates' and colleagues' assumptions and normative expectations, and wider group-based participation in 'pro-democracy' or 'anti-student' discourses. However, rather than engaging in exhaustive analyses of this kind, in this article I have chosen to adopt the three meanings of plus qu'une langue as a way of focusing on the interconnections of the disparate dimensions, rather than on their separateness.

\section{Plus qu'une langue 2: more than one indivisible language}

The second sense of plus qu'une langue explored here is that of more than (or not only) one indivisible language. Popular conceptions of multilingualism often assume that the notion of 'competence', as it applies to second or additional languages, is comparable to that which applies to first or native languages, and that it should be assessed using monolingual native speakers as benchmarks. In contrast, Blommaert (2010, p. 169) notes the prevalence of 'truncated repertoires' - people have some facility in several languages, but their skills profile may look unbalanced or even deficient if viewed through the traditional, monolingual lens of 'proficiency'. In addition, the monolingual viewpoint tends to ignore the creative potential of combining elements from different languages and using non-linguistic resources. While Yasmina's proficiency level in conventional terms is quite low, this does not prevent her from engaging in identity work by drawing on linguistic and non-linguistic resources in individual and creative ways. For example, in her techno-linguistic report (TLR) Yasmina noted that although she seldom uses French on Facebook, she has nevertheless written 'quite a few posts with French words'. One such post, appearing under a picture of a stormy Hong Kong skyline, went as follows:

finally home. quirky weather. exhausted soul. bonsoir chez moi. [good night my home] 


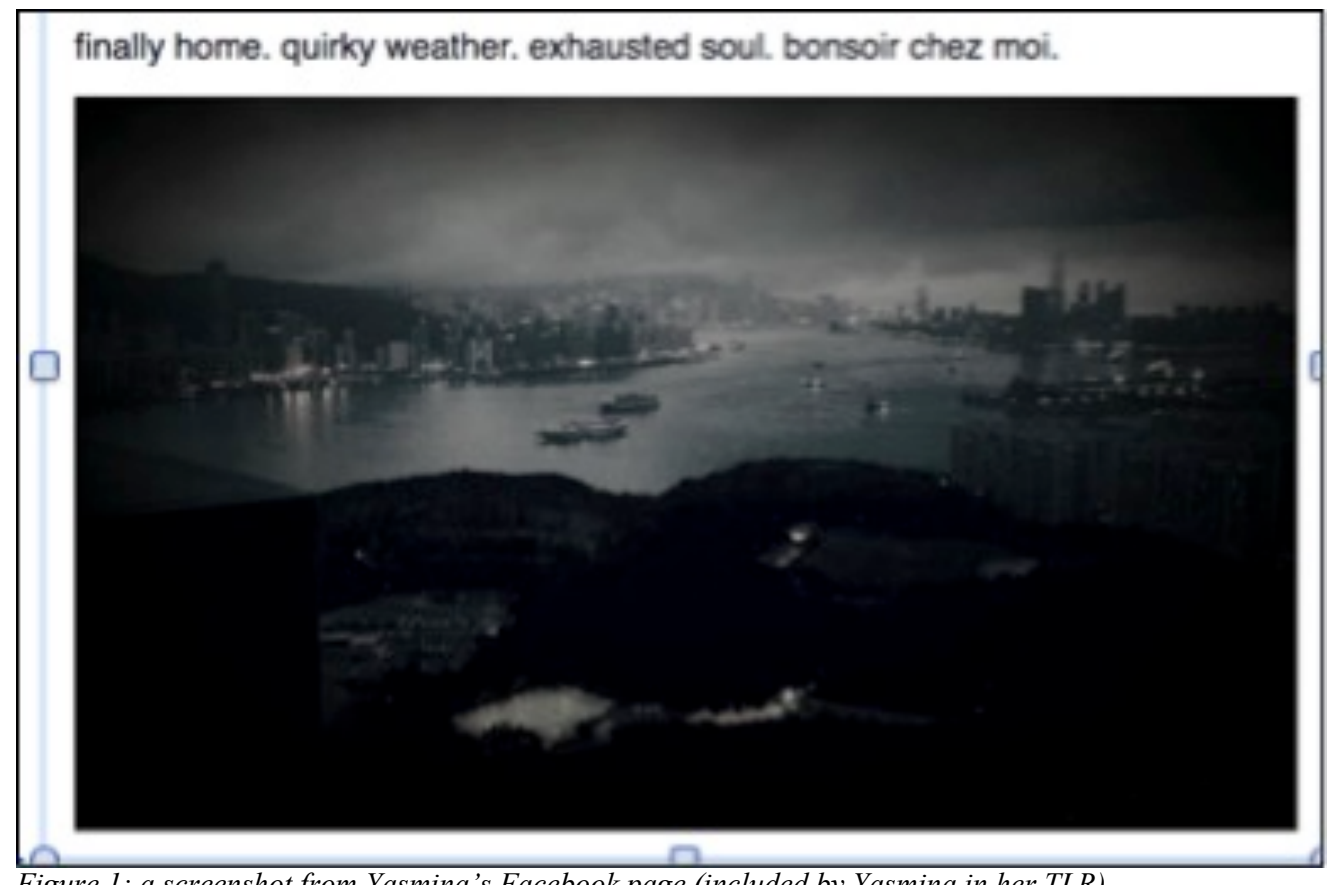

Figure 1: a screenshot from Yasmina's Facebook page (included by Yasmina in her TLR).

Instead of relying on language alone, Yasmina's post draws on visual and typographic resources and their associated semiotic potential in order to create a situated, projected identity. She explains this use of French words as being 'somehow poetic to the moments whilst I would like to share to friends' (TLR). She observes that the combination of images and words 'actually creates another possibility for the language itself [...] people will link this image and this kind of expression of language together to present the idea of Frenchness' (INT2). The meaning of familiar phrases such as bonsoir and chez moi is being extended and personalized through their contextualization with English words and striking visuals of the Hong Kong skyline. In her study of identity practices among multilingual Facebook users, Chen (2013) also observes that the construction of identities 'is not limited to linguistic codes but to the symbolic resources that are available to multilingual learners to explore the sense of who they are and their relationship to the world' (p. 162).

The sense of 'divisibility' also applies to cultural representations. In addition to appropriating elements of French in her own way, for her own purposes, Yasmina has also tried to discover what lies behind the stereotypical representations of French culture. Learning about other cultures and relating them to her own has encouraged Yasmina to look for differences within them:

I want to explore more in French [...] is it the same as what I explored right now or are there other possibilities in this language? Because...I think for most of people they learn French because it's so poetic, it sounds so elegant [...] but is it romantic the only thing in French? [...] Why not political and euh philosophical? There're a lot of different kinds of elements in French, this language (INT2)

In other words, rather than uncritically adopting languages as unitary, clearly-bounded entities, 
learners creatively appropriate and combine disparate resources in order to refashion their identities.

\section{Plus qu'une langue 3: more than one isolated language}

The third sense of plus qu'une langue considered here is that of more than one, isolated language - i.e., it is important to consider the interrelationships of languages, both in terms of learners' perceptions and of what might be called the language ecology (Haugen, 1972) of the local context. Perceptions of languages, and their associated cultures, depend on perceptions of other languages and cultures. In Hennig (2010), for example, learners of German perceive it as a 'tough' language, but this is enabled and enhanced by the simultaneous perception of French as a 'romantic' language (p. 312). Although this arguably applies to all language learning it is perhaps especially true for additional languages; as they are not widely used, learners create their own understandings of similarities and differences through their impressions and experiences. They then relate these languages and cultures to each other, and to their own, suggesting the interconnections between the relational, reflexive and imaginative aspects of identity.

Yasmina's accounts of her two additional languages - Japanese and French - illustrate some of these relationships. In narrating her trips to Japan, Yasmina recounts her impressions of how efficient and smooth social life is, and of how Japanese people seem to be proud of this. However, and continuing the 'critical' orientation noted above, she also voices some skepticism about such an apparently perfect social order:

at first, you would think it's fascinating, "Oh, how can the social order be running so perfectly?"... everybody knows what's happening, they're very aware of others, but [the] more you find out and communicate with really Japanese people and... you found out they're really worried about others' thoughts (INT1)

By way of contrast with Japanese, she describes French culture as something in which people have no fear of expressing themselves. She recalls a particular incident where a waiter in France gave a 'bitch face' (an unfriendly impression; INT2), but she saw this as somehow 'a good thing' that was linked to another impression of France, that of 'relaxedness':

I had a really really strong ((laugh)) strong impression on the waiter in France. They want euh... if they wanted to give you bitch face, they would really give you the bitch face ((laugh)). It's kind of euh "I don't really want to do it, but I have to do it so I give it to you!" showing their real own self (INT2)

This observation makes her think that French people are 'carefree in life' and true to themselves (INT2) and that being fluent in French would allow her 'to be more natural or truly to myself' (INT3), in contrast with Hong Kong culture which is seen not to allow freedom of expression since the social codes of behaviour are very different:

And I think it's easier to express yourself in a free culture. Actually in HK, it seems so free! It seems so so euh flexible for you to speak about anything, but in the end it's not the same ((laugh)) not this kind of free, it's euh there are a lot of hidden agendas, a lot of restrictions that you might not notice (INT2) 
This contrast between French 'freedom' and Hong Kong 'restriction' also appears at a linguistic level when Yasmina describes aspects of French and Cantonese. She recounts the example of a question/answer sequence that was in wide circulation on social media at the time of the interview, namely 'Can you say something sexy in French?' 'Non!' For Yasmina, this seemed to represent the freedom and assertiveness of French culture:

it sounds very French [...] When you say Non or Oui and people would all... of course they will know it's French [...] Like you're expressing something... something relaxed... in relax and yet you're relaxed and you're confirmed with what you're saying (INT2)

But rather than staying with the France/Hong Kong, freedom/restriction binary, Yasmina noted that Cantonese had similar resources and indexical potentials. She described how people were using Cantonese in creative ways, for example in forums such as HKGolden, to achieve a kind of free expression:

there are a lot of events and incidents happening in HK and those symbols and those words become another thing, they embody another meaning... after the events like the Yellow Umbrella ((referring to the 2014 student protests in Hong Kong)) it has a different kind of meaning, a political meaning now (INT2)

Yasmina had at one stage chosen the adjectives 'funny', 'lively' or 'alive' (INT2) to describe Cantonese. However, she also explained that Cantonese is not only 'funny' but is also used to make fun of and criticise others, a phenomenon that has become more noticeable since the 2014 student movement in online forums or on Facebook.

These comments show how individual perceptions of languages are formed in a relational manner within a wider socio-political environment comprised of various spatial and temporal scales. There is a reliance on established beliefs and values about languages and their speakers (Bucholtz \& Hall, 2005, p. 594), coupled with individual, local inflections and influences. In the case of Hong Kong, language has become an important resource in asserting and discussing local identity, which has become a sensitive issue since the 2014 protests.

Thus, and to expand on relational identity and Coffey's (2010) notion of 'points of sameness and difference' (p. 125), Yasmina has made a series of connections and comparisons between languages and their associated cultures. French initially represented one pole of a freedom/restriction opposition. Hong Kong was then seen as having both differences and similarities. Although Hong Kong society was perceived to be less 'free', both Cantonese and French provide affordances for assertive self-expression. The process of 'reaching out' to explore another culture is also a process of 'coming back' to reflect upon and reimagine one's own culture, showing how the relational aspect of identity is linked with the reflexive and imaginative aspects. Secondly, these connections illustrate the interaction among all three dimensions of the narrative inquiry space - the individual and the social (sociality), the spatial, and the temporal, or the who, the where, and the when - at a time where young people in Hong Kong are concerned about the future of the space they call home.

\section{Discussion and conclusion}


The three senses of plus qu'une langue draw attention to three aspects of the relationship between additional language learning and identity: their significance in providing resources for identity construction, despite limited levels of proficiency; the way they are subject to creative appropriation according to individual and broader contextual factors; and the way in which they are relational in terms of gaining their meanings and potentials from other languages in learners' repertoires. Although this might be said to apply to all language learning, it is worth reiterating that this is despite there not being much scope for 'using' additional languages, or even for achieving 'proficiency', in the conventional sense of these terms. Indeed, it is possible to argue that additional languages, by virtue of being less visible, less institutionally controlled, and free from the negative associations of compulsory schooling, provide as much potential for identity work as dominant second languages such as English. The fact of being less known as languages, while still having their cultural associations widely circulated in the media, provides more space for imaginative and creative appropriation. Compared with dominant languages their use is less likely to be normed by others, and their minority status gives them distinction by creating 'small spaces of uniqueness' (Blommaert \& Varis, 2015, p. 27).

From the perspective of the three-dimensional narrative space, what Yasmina's accounts show in their entirety is the interrelationship of the dimensions, and the ways in which individuals can draw on various resources in dealing with limitations and restrictions of various kinds. The discovery of difference at a global spatial scale is related back to a rediscovery of the local spatial scale, and involves a process of reflection on similarity/difference and one's own position within the social environment. For Yasmina, learning about additional languages and their cultures seems to be a way to negotiate her way into her own society by learning how to communicate more effectively, gaining confidence, and having her individuality accepted and recognized by others, but all in a way that avoids confrontation. The temporal dimension appears as a concern with possible futures, something that resonates with the poststructuralist view of identity (e.g., '[i]dentities are about negotiating new subject positions at the crossroads of the past, present and future', according to Block, 2007, p. 27; see also Norton, 2000).

At first sight, the role of additional languages may appear to be one of providing examples of difference, and inspiring a kind of agentic resistance to the undesirable aspects of the local culture. However, Yasmina seems to be using additional languages to help overcome unfavourable identities imposed by the local culture and its institutional practices, including those associated with dominant languages (see also Wortham, 2004). These 'acts of resistance', acts that are also 'acts of identity' in Le Page and Tabouret-Keller's (1985) terms, are undertaken in individual and creative ways. Yasmina is not learning additional languages merely for instrumental reasons of career enhancement, or for narrowly integrative reasons if these are defined in relation to a pre-existing 'target community'. For Yasmina, additional language learning is also an act of agency, something that can enable learners to 'react to given societal circumstances in their own way' (Hennig, 2010, p. 310).

Thus, resistance is insufficient to characterise what appears to be going on. There is also reflection in the way Yasmina applies insights from 'outside' to achieve a different perspective on the 'inside' in both personal and local terms. Although Benson et al. (2013, p. 104) report that some participants gain 'increased objectivity' about their culture vis-à-vis other cultures, leading them to avoid idealisations and emphasize similarities over differences, Yasmina's accounts suggest a more complex process in which differences are still acknowledged and are used to re- 
appraise both the 'global' and the 'local'. This process of inter- and intra-cultural awareness involves a reconfiguration of personal identity via the interactions of its relational, reflexive and imaginative aspects.

The findings reflect some of the particularities of additional language learning, along with specific aspects of the local context and of the participants. However, if it is accepted that the Hong Kong context illustrates how the phenomena of globalisation - including mobility, hybridity and extensive online interaction - influence language learning, then they also suggest some of the more general aspects of language learning under contemporary conditions. The picture of identity that emerges here is complex and dynamic, and further confirms that static views of the self, homogeneous 'local' identity categories and stereotypical representations of 'global' target languages cannot do justice to the interplay between learner identity and additional language learning. The narrative inquiry approach adopted by the study provides conceptual and methodological tools with which to understand this interplay. Narrative data help to illustrate some of the language phenomena associated with globalization, as described by terms such as metrolingualism ('the complex ways in which fluid and fixed, as well as global and local, practices reconstitute language and identities'; Otsuji \& Pennycook, 2010, p. 247). In today's world, additional language learning provides individuals such as Yasmina with the possibility of liberation from 'sensitive language boundaries and fault lines' (Lamoureux 2012, p. 152).

The significance of the study extends to its pedagogical implications. The view of contemporary language learning that emerges here has the potential to change the way an additional language classroom is conceived, into a place where language learning contributes to the development of the self and where learners are offered opportunities to 'own the target language' and gain 'more powerful identity positions for the future' (Ollerhead, 2012, p. 79). Learning proceeds from existing identity positions, even as it changes them. Learners need varied opportunities to exercise their agency and reconfigure these identities, instead of being subjected to a single imposed identity (that of the beginner student) and a single task (approximating the language forms of native speakers). Within a context of conventional language education that keeps languages separate and assumes monolingual norms and practices as its target, the study counterposes the existence and significance of learners' multilingual practices and repertoires. The third sense of plus qu'une langue identified above - the relational ecology of languages within multilingual repertoires - points to the desirability of integrating these languages, along with their potential for identity construction and creativity, into the language learning classroom. This is in line with perspectives such as translanguaging (Garcia \& Li Wei, 2014) and plurilingualism (Moore \& Gajo, 2009). Questions of language and identity also need to be raised during teacher training, so that teachers can recognize 'which identity positions offer their learners the best prospects for social engagement and interaction' (Ollerhead, 2012, p.79). In more general terms, the study has illustrated how the relationship between language learning and identity involves multiple factors at different levels of context, involving various affordances and constraints. Future research could further explore how these factors interact for other learners and contexts; narrative approaches help to foreground the particularity of individual cases and avoid the tendency to impose reductive or linear models of causation. Both research and teaching need to move beyond 'apolitical appreciation and celebration of foreign culture', and to explore both the diversity and the sociopolitical context of human communication (Kubota et al., 2003, p. 22). 


\section{Notes}

Transcription conventions:

... three dots

-> a tiny 'gap' within or between utterances

Euh

-> hesitation within or between utterances

Italics

-> foreign word e.g., in French such as Bonjour

$[\ldots]$

-> material omitted by researcher

((transcriber's notes or descriptions))

$\rightarrow(($ laugh $))$

\section{References}

Barbour, R. (2000). The role of qualitative research in broadening the 'evidence base' for clinical practice. Journal of evaluation in clinical practice, 6(2), 155-163.

Barbour, R. (2008). Introducing qualitative research. London: Sage Publications.

Barkhuizen, G. (2009). An extended positioning analysis of a pre-service teacher's better life small story. Applied Linguistics, 31(2), 282-300.

Barkhuizen, G. (2011). Narrative knowledging in TESOL. TESOL Quarterly, 45(3), 391-414.

Barkhuizen, G. (2016). A short story approach to analyzing teacher (imagined) identities over time. TESOL Quarterly, 50(3), 655-683.

Barkhuizen, G. (2017). Investigating language tutor social inclusion identities. The Modern Language Journal, 101(S1), 61-75.

Barkhuizen, G., Benson, P., \& Chik, A. (2014). Narrative inquiry in language teaching and language research. London and New York: Routledge.

Benson, P., Barkhuizen, G., Bodycott, P. \& Brown, J. (2013). Second language identity in narratives of study abroad. Basingstoke: Palgrave MacMillan.

Bland, B. (2017). Generation HK: Seeking identity in China's shadow. Australia: Penguin Group. 
Block, D. (2007). Second language identities. London and New York: Continuum.

Blommaert, J. (2010). The sociolinguistics of globalization. Cambridge: Cambridge University Press.

Blommaert, J. \& Varis, P. (2015). Enoughness, accent and light communities: Essays on contemporary identities. Tilburg Papers in Culture Studies, 139.

Bruner, J. (2001). Self-making and world-making. In J. Brockmeier \& D. Carbaugh (Eds.), Narrative and identity: Studies in autobiography, self and culture (pp. 25-37). Amsterdam: John Benjamins.

Bucholtz, M. \& Hall, K. (2005). Identity and interaction: a sociocultural linguistic approach. Discourse Studies 7, 585-614.

Byrd Clark, J. (2012). Introduction: Journeys of integration between multiple worlds: reconceptualising multilingualism through complex transnational spaces. International Journal of Multilingualism, 9(2), 132-137.

Canagarajah, S. \& De Costa, P. (2016). Introduction: Scales analysis, and its uses and prospects in educational linguistics. Linguistics and Education 34, 1-10.

Chen, H. I. (2013). Identity practices of multilingual writers in social networking spaces. Language Learning \& Technology, 17(2), 143-170.

Clandinin, D. J. (2013). Engaging in narrative inquiry. Walnut Creek, CA: Left Coast Press.

Clandinin, D. J. \& Rosiek, R. (2007). Mapping a landscape of narrative inquiry: Borderland spaces and tensions. In D.J. Clandinin (Ed.) Handbook of narrative inquiry: Mapping a methodology (pp. 35-76). Thousand Oaks, CA: Sage Publications.

Clandinin, D. J. \& Connelly, F.M. (2000). Narrative inquiry: Experience and story in qualitative research. San Francisco, CA: Jossey-Bass.

Clarke, M., \& Hennig, B. (2013). Motivation as Ethical Self-Formation. Educational Philosophy and Theory, 45(1), 77-90.

Coffey, S. (2010). Stories of Frenchness: Becoming a francophile. Language and Intercultural Communication 10(2), 119-136.

Darvin, R. \& Norton, B. (2015). Identity and a model of investment in applied linguistics. Annual Review of Applied Linguistics, 35, 36-56.

De Angelis, G. (2007). Third or additional language acquisition. Clevedon: Multilingual Matters.

De Costa, P. (2010). From refugee to transformer: A Bourdieusian take on a Hmong learner's trajectory. TESOL Quarterly 44(3), 517-541. 
De Fina, A. (2006). Group identity, narrative and self-representations. In A. De Fina, D. Schiffrin \& M. Bamberg (Eds.), Discourse and identity (pp. 351-375). Cambridge: Cambridge University Press.

Dreyer, S. (2009). Apprentissage du francais et motivation existentielle. Le cas des universités à Taiwan. Lidil, 40 (online). Available at http://lidil.revues.org/2911 (Accessed on 14 Apr. 2019)

Duff, P. A. (2014). Case study research on language learning and use. Annual Review of Applied Linguistics, 34, 233-255.

Eakin, P. J. (1999). How our lives become stories: Making selves. Ithaca, NY: Cornell University Press.

Francis, R. (2010). The decentring of the traditional university: The future of (self) education in virtually figured worlds. London: Routledge.

Gao, Xuesong A. (2010). Autonomous language learning against all odds. System 38, 580-590.

Garcia, O. \& Li Wei. (2014). Translanguaging: Language, bilingualism and education. Basingstoke, UK: Palgrave MacMillan.

Gu, M. M. (2010). Identities constructed in difference: English language learners in China. Journal of Pragmatics 42(1), 139-152.

Gu, M. M. (2011). Language choice and identity construction in peer interactions: Insights from a multilingual university in Hong Kong. Journal of Multilingual and Multicultural development, 32(1), 17-31.

Hammarberg, B. (2010). The languages of the multilingual: Some conceptual and terminological issues. IRAL-International Review of Applied Linguistics in Language Teaching 48(2-3), 91104.

Harré, R. (2001). Metaphysics and narrative: Singularities and multiplicities of self. In J. Brockmeier \& D. Carbaugh (Eds.), Narrative and identity: Studies in autobiography, self and culture (pp. 59-73). Philadelphia: John Benjamins Publishing.

Haugen, E. I. (1972). The ecology of language: Essays by Einar Haugen. Selected and Introduced by Anwar S. Dil. Stanford: Stanford University Press.

Hennig, B. B. (2010). Language learning as a practice of self-formation. International Journal of Multilingualism 7(4), 306-321.

Ho, L. (2000). Hong Kong writing and writing Hong Kong. World Englishes, 19(3), 381-386.

Humphreys, G. \& Spratt, M. ( 2008). Many languages, many motivations: A study of Hong 
Kong students' motivation to learn different target languages. System 36(2), 313-335.

Jessner, U. (2008). Teaching third languages: Findings, trends and challenges. Language Teaching 41(1), 15-56.

Kanno, Y. \& Norton, B. (2003). Imagined communities and educational possibilities. Journal of Language, Identity and Education 2(4), 241-249.

Kinginger, C. (2004). Alice doesn't live here anymore: Foreign language learning and identity reconstruction. Negotiation of identities in multilingual contexts, 21(2), 219-242.

Kubota, R., Austin, T., \& Saito-Abbott, Y. (2003). Diversity and inclusion of sociopolitical issues in foreign language classrooms: An exploratory survey. Foreign Language Annals, $36(1), 12-24$.

Lamoureux, S. A. (2012). 'My parents may not be French sir, but I am': Exploration of linguistic identity of Francophone bilingual youth in transition in multicultural, multilingual Ontario. International Journal of Multilingualism, 9(2), 151-164.

Le Page R. B. \& Tabouret-Keller, A. (1985). Acts of identity: Creole-based approaches to language and ethnicity. Cambridge: Cambridge University Press.

Lincoln, Y. \& Guba, E. (1985). Naturalistic inquiry. Beverly Hills, CA: Sage.

Loh, J. (2013). Inquiry into issues of trustworthiness and quality in narrative studies: A perspective. Qualitative Report, 18(33), 1-15.

Menard-Warwick, J. (2005). Both a fiction and an existential fact: Theorizing identity in second language acquisition and literacy studies. Linguistics and Education, 16(3), 253-274.

Mercer, S. (2013). Working with language learner histories from three perspectives: Teachers, learners and researchers. Studies in Second Language Learning and Teaching, 3(2), 161185.

Mishler, E. (2006). Narrative and identity: The double arrow of time. In A. De Fina, Schiffrin, D. and Bamberg, M. (Eds.), Discourse and Identity (pp. 30-47). Cambridge: Cambridge University Press.

Moore, D., \& Gajo, L. (2009). Introduction-French voices on plurilingualism and pluriculturalism: Theory, significance and perspectives. International Journal of Multilingualism, 6(2), 137-153.

Morita, N. (2004). Negotiating participation and identity in second language academic communities. TESOL Quarterly 38(4), 573-603.

Norton, B. (2000). Identity and language learning: Gender, ethnicity and educational change. Harlow: Pearson. 
Norton, B. (2012). Identity and second language acquisition. In C. A. Chapelle (Ed.), The encyclopedia of applied linguistics (pp. 1-8). Oxford: Blackwell.

Norton, B. \& Toohey, K. (2011). Identity, language learning, and social change. Language Teaching 44(4), 412-446.

Ollerhead, S. (2012). "Passivity" or "Potential"? Teacher responses to learner identity in the lowlevel ESL classroom. Literacy and Numeracy Studies 20(1), 1-13.

Otsuji, E., \& Pennycook, A. (2010). Metrolingualism: Fixity, fluidity and language in flux. International Journal of Multilingualism, 7(3), 240-254.

Pavlenko, A. (2002) Poststructuralist approaches to the study of social factors in second language learning and use. In V. Cook (Ed.), Portraits of the L2 user. Clevedon: Multilingual Matters, 277-302.

Pavlenko, A. \& Norton, B. (2007). Imagined communities, identities, and English language teaching. In Cummins, J. \& Davidson, C. (Eds.), International Handbook of English Language Teaching, (pp. 669-680). New York: Springer.

Pennycook, A. (2010). Language as a Local Practice. Abingdon, UK: Routledge.

Polkinghorne, D.E. (1988). Narrative knowing and the human sciences. Albany: State University of New York Press.

Polkinghorne, D. E. (1995). Narrative configuration in qualitative analysis. International Journal of Qualitative Studies in Education, 8(1), 5-23.

Riessman, C. K. (1993). Narrative analysis. Newbury Park, California: Sage Publications.

Sarangi, S. \& Candlin, C. N. (2003). Introduction: Trading between reflexivity and relevance: New challenges for applied linguistics. Applied Linguistics, 24(3), 271-285.

Schiff, B. \& Noy, C. (2006). Making it personal: shared meanings in the narratives of Holocaust survivors. In De Fina, A., Schiffrin, D. and Bamberg, M. (Eds.), Discourse and Identity (pp. 30-47). Cambridge: Cambridge University Press.

Shedivy, S. L. (2004). Factors that lead some students to continue the study of foreign language past the usual 2 years in high school. System, 32(1), 103-119.

The Asian mobile consumer decoded. (2014). Nielsen. Available at: http://www.nielsen.com/ph/en/insights/news/2014/asian-mobile-consumers.html (Accessed Jan 24, 2017).

Toohey, K. (2000). Learning English at school: Identity, social relations and classroom practice. Clevedon: Multilingual Matters. 
Weedon, C. (1987). Feminist practice and poststructuralist theory. Oxford: Basil Blackwell.

Wells, K. (2011). Narrative inquiry. Cambridge: Cambridge University Press.

Wenger, E. (1998). Communities of practice: Learning, meaning, and identity. New York: Cambridge University Press.

Wortham, S. (2004). The interdependence of social identification and learning. American Educational Research Journal, 41(3), 715-750.

Wortham, S. (2005). Socialization beyond the speech event. Journal of Linguistic Anthropology, 15(1), 95-112. 